\title{
Mark S. Persky, Milton Waner, Francine Blei, Alejandro Berenstein: Vascular lesions of the head and neck: Diagnosis and management
}

\author{
Thieme Verlag: Stuttgart, New York, Delhi, Rio, December 2014, 1st Edition, 168 pp, \\ 236 illustrations, US\$ 99.99 (Hardback), ISBN: 978-1-60406-059-1; ISBN (Americas): \\ 9781604060591; ISBN as an e-book: 978-1-62623-087-3
}

\author{
Pierre Kehr \\ Received: 15 December 2014/ Accepted: 28 December 2014/Published online: 4 February 2015 \\ (C) Springer-Verlag France 2015
}

This book has vascular malformations of the head and the neck persons in charge in the children or the young adults of disfigurations, bleedings or functional disorders. The congenital or tumoral origin of these malformations made a longtime them difficult to treat, whereas technological progress allowing a precise diagnosis and the best knowledge of their evolution bring tools able to currently carry out an effective management.

The book constitutes a collective work of more than 20 authors specialists in the various described lesions. A first chapter describes the classification of the vascular anomalies with conclusive photographs. An important development is then devoted to the hemangiomas, their diagnosis, their evaluation, the various syndromes, the radiological evaluation and finally the treatment of the infantile hemangiomas.
The endovascular surgery, the surgery of vascular malformations, finally the evaluation and the treatment of the vascular neoplasms finish the work.

A very detailed index allows a rapid access with the various entries. The book comprises very many color photographs which will allow easy clinical comparisons.

This book intended for the specialists is also to advise with the doctors, in particular with the pediatrists confronted in their practice with these malformations, because they will be able to thus better direct the young patients toward the effective modern treatments.

Conflict of interest None.
P. Kehr $(\bowtie)$

Strasbourg, France

e-mail: pierre.kehr@gmail.com 